Corrigendum

\title{
Corrigendum to "Effects of Presowing Pulsed Electromagnetic Treatment of Tomato Seed on Growth, Yield, and Lycopene Content"
}

\author{
Aspasia Efthimiadou, ${ }^{1}$ Nikolaos Katsenios, ${ }^{2}$ Anestis Karkanis, ${ }^{3}$ Panayiota Papastylianou, \\ Vassilios Triantafyllidis, ${ }^{4}$ Ilias Travlos, ${ }^{2}$ and Dimitrios J. Bilalis ${ }^{2}$ \\ ${ }^{1}$ Open University of Cyprus, P.O. Box 24801, 1304 Nicosia, Cyprus \\ ${ }^{2}$ Laboratory of Crop Production, Agricultural University of Athens, Iera Odos 75, 11855 Athens, Greece \\ ${ }^{3}$ Department of Agriculture Crop Production and Rural Environment, University of Thessaly, \\ Fytokou Street, N. Ionia, 38466 Magnisia, Greece \\ ${ }^{4}$ Department of Business Administration of Food and Agricultural Enterprises, University of Patras, \\ Seferi Street 2, 30100 Agrinio, Greece \\ Correspondence should be addressed to Nikolaos Katsenios; nkatsenios@hotmail.com \\ Received 12 February 2016; Accepted 9 June 2016
}

Copyright (C) 2016 Aspasia Efthimiadou et al. This is an open access article distributed under the Creative Commons Attribution License, which permits unrestricted use, distribution, and reproduction in any medium, provided the original work is properly cited.

In the article titled "Effects of Presowing Pulsed Electromagnetic Treatment of Tomato Seed on Growth, Yield, and Lycopene Content", [1] Figure 4 showing the PAPIMI device was already published in a previous article by the authors, which was cited as reference 13. Figure 4 should be replaced with the following figure.

\section{References}

[1] A. Efthimiadou, N. Katsenios, A. Karkanis et al., "Effects of presowing pulsed electromagnetic treatment of tomato seed on growth, yield, and lycopene content," Scientific World Journal, vol. 2014, Article ID 369745, 6 pages, 2014. 


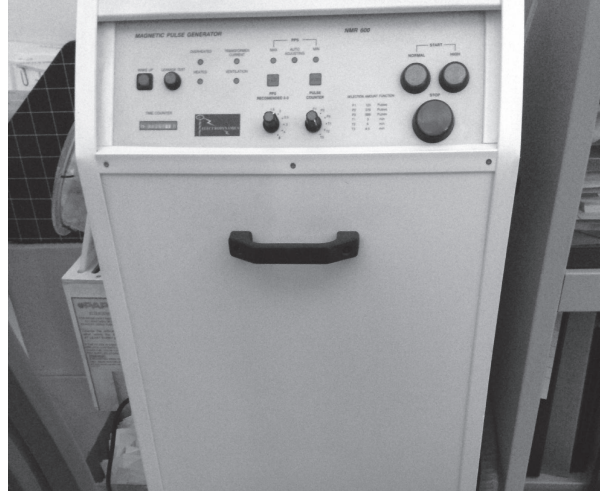

FIgURE 4: PAPIMI device. 


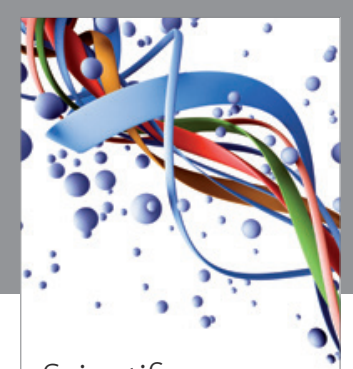

Scientifica
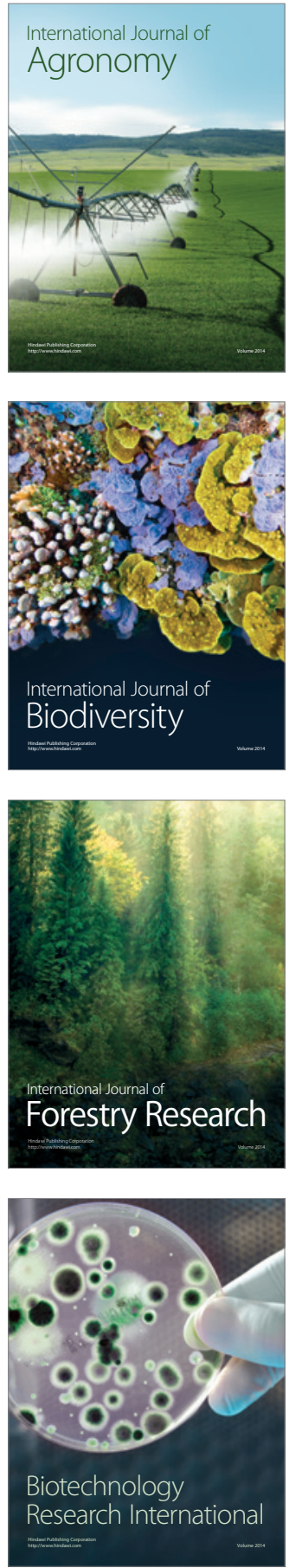
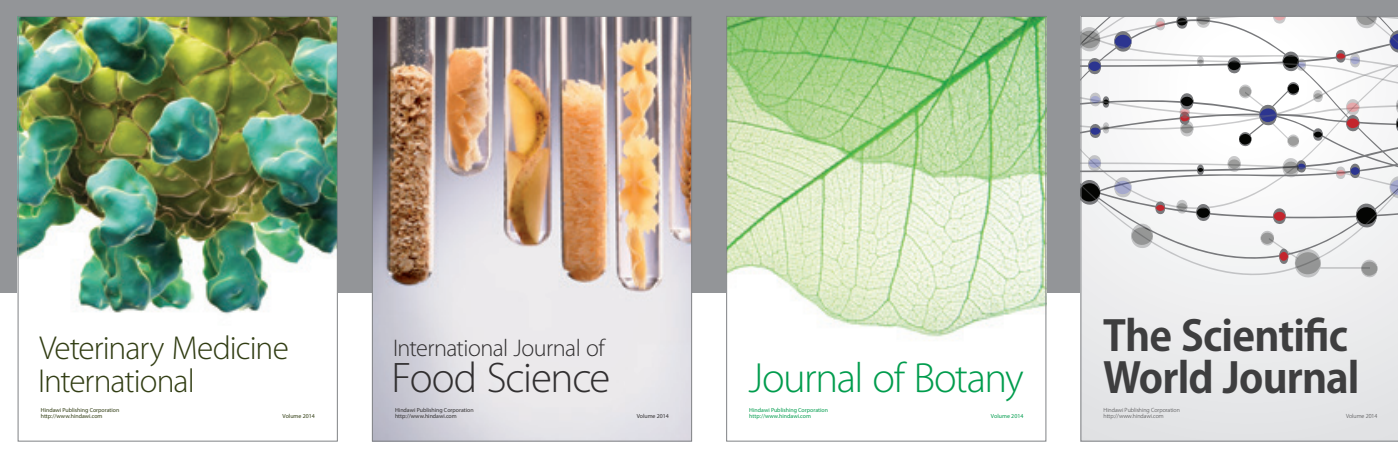

The Scientific

\section{World Journal}

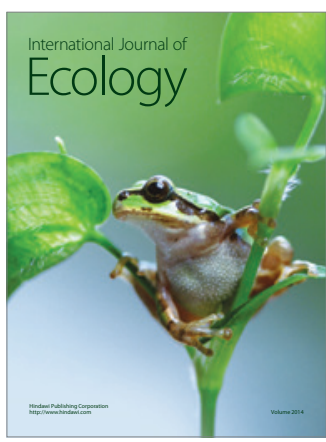

\section{Hindawi}

Submit your manuscripts at

http://www.hindawi.com
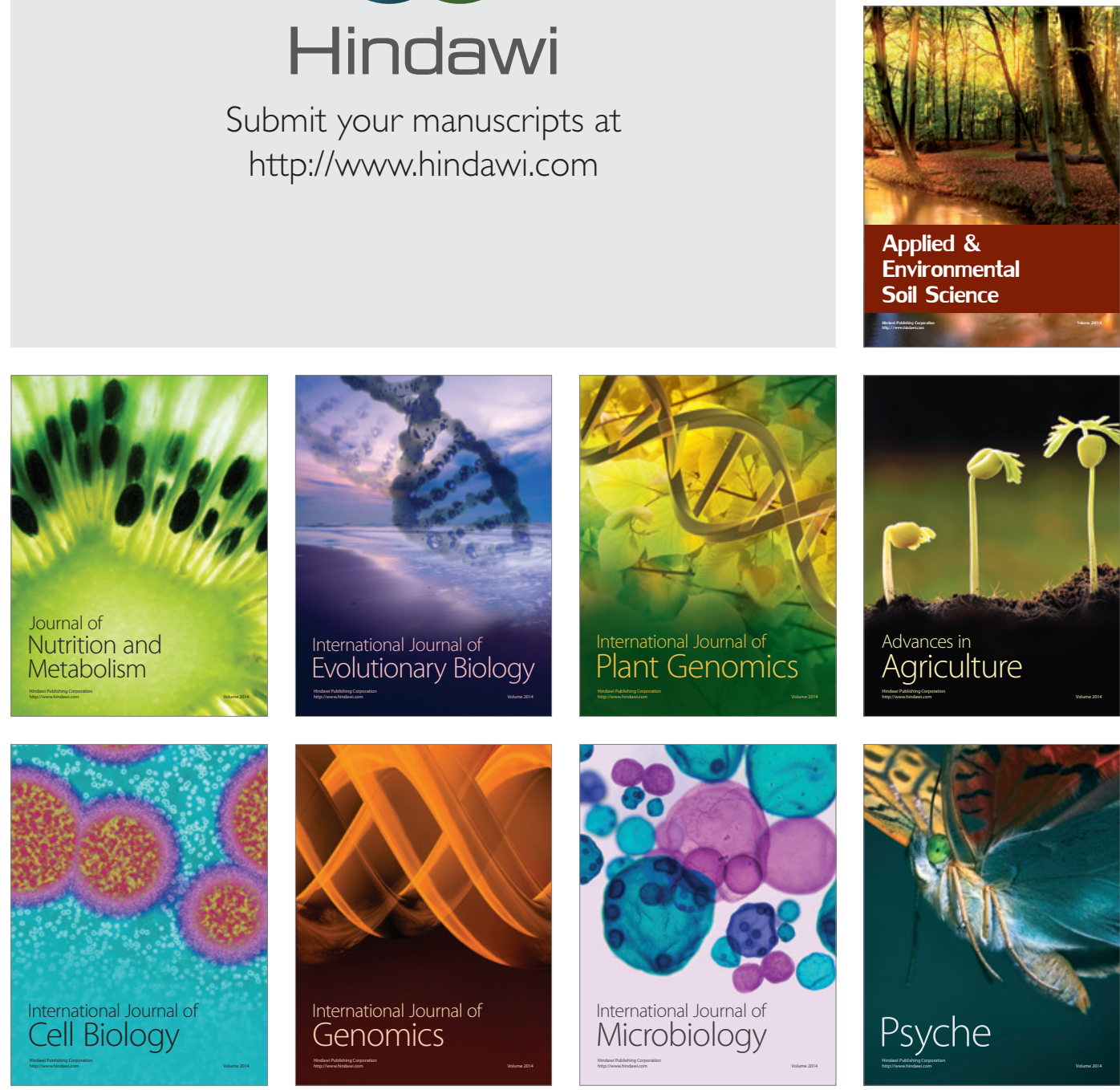
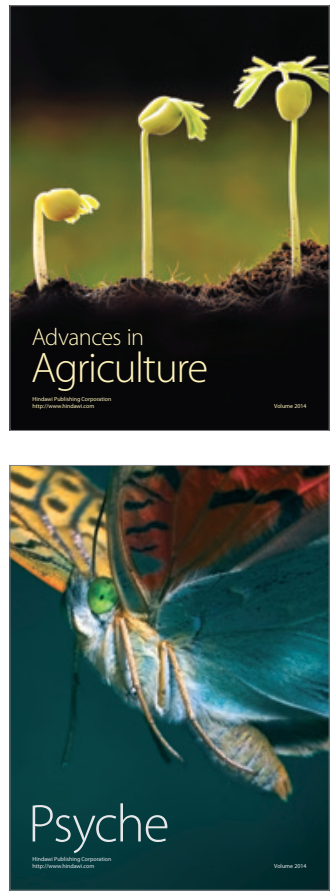